\title{
Controlling Reactor Power of CARR with A Fuzzy Logic Controller
}

\author{
Hai Zeng \\ Department of Reactor Engineering Design, China Institute of Atomic Engergy, Beijing 102413, P. R. China
}

\begin{abstract}
To demonstrate the applicability and feasibility of AI technology in nuclear fields in China, a fuzzy controller to control the reactor power of China Advanced Research Reactor (CARR) is designed in this paper. The fuzzy controller uses Mamdani inference system based 2 inputs-power difference and power period, 1 output- velocity of control rods. To evaluate the performance of the fuzzy controller, the simulation models of the closed-loop system are set up based on SIMULINK flat. Simulations of 4 transients are computed, which are reactor starting from subcriticality to low reactor power, reactor power increasing from low power to full power, reactor decreasing from full power to low power, and transient under step reactivity disturb. Simulations result show good performance of the fuzzy controller in these 4 transients.
\end{abstract}

Keywords: Fuzzy controller, Simulation, CARR

\section{Introduction}

The control system is one of the most important systems for nuclear power plants (NPPs) or research reactors. The stability and performance will have great impact on the operation of NPPs or reactors. For the long time, the control system of NPPs or reactors is based on classical control theory, and classical PID controllers are dominant in nuclear fields because of the strict safety requests on nuclear reactor, even though the control theory has evolved from classical theory to modern control theory, and to advanced control theory which is represented by artificial intelligence (AI) technology.

Compared with classic and modern control theory, AI technology has many advantages [1]-[2]:

1) AI technology was derived from the reasoning process of human brain or evolution process of biological species, so the accurate mathematic description of industry process is not indispensable, and it is very difficult to describe a real industry process- the operation of a nuclear power unit, for instance- as a simple but accurate mathematic model. The classic and modern control theory is based on the mathematic model, and relies to great extent on the accuracy of the model, that will inevitably increase the complexity of model and theory analysis.

2) The engineering uncertainty is allowed by AI technology. But classic and modern control theory demand that the model is as identical as possible with the actual industry process, and big difference between them will necessitate the re-analysis and re-design of control system.

3) The AI based controller, which is self-adaptive because of its self-training function, will save the field commissioning time and cost. It can optimize itself to be consistent with the actual industry process. The classic and modern theory based controller need field control parameters tuning, it has some but narrow adaptability if complex algorism is used.

4) The comprehensive theory analysis of the whole closed loop is essential for the design of a classic or modern controller, and adds more technical difficulty to a control engineer. The AI based controller, fuzzy controller, for instance, which is based on the operating experience of operators, is easy to be understand and implemented because of its simple principle.

5) AI technology is fitted to large-scale and nonlinear industry process, but there still is technical limitation for classic and modern control theory to ravel out the non-linearity problem of system.

6) AI technology can realize the real-time diagnosis of any abnormality, fault, or transient of instrument channel, key device, system, or the whole plant, instead it is difficult for conventional technology to do so. Firstly operator can take protective counter measurement beforehand, which will enhance greatly the safety of reactor; secondly the present periodic maintenance can be replaced by predictive maintenance, which increases the availability, and surely the economy of reactor.

AI technology emerged in 60's of last Century, made great progress in 80 's- 90 's, and was applied in reactor control field successfully in 90's. The operation and control of the new generation NPPs will increasingly not rely on operators but control system 
to accomplish the judgment and control of steady state or transient process, which will necessitate the enhanced automation of NPPs. The objective of future NPPs is autonomous or semi- autonomous operation of plants [3], AI technology will be a good option to match this trend. With the development of computation and computer technology, there are many researchers and engineers in foreign countries working on implementation of AI technology in nuclear field, and AI technology will be the trend of reactor control system. Comparatively there is less R\&D work on AI in China, and no real implementation. Reactor control technology, which is an important part of nuclear reactor technology, should be consistent with the trend of technical independence and localization. So it is important to carry on the research and development work of AI technology implementation at the coming moment of the great development of Chinese nuclear electricity industry. As well known Chinese nuclear industry is stepping into a new prospering era now. According to the nuclear power program of China, the total nuclear power unit capacity will reach $40,000 \mathrm{MWe}$, about $4 \%$ of the total electricity capacity in 2020. This means that $281000 \mathrm{MWe}$ nuclear power units will be constructed during 2005 and 2020. For these new units, people demand much higher safety and economy than before. AI should be a good option to meet this demand.

\section{CARR and its control system}

In China Institute of Atomic Energy (CIAE), a new research reactor -China Advanced Research Reactor (CARR)- is being constructed now [4]. CARR is a large neutron science facility with reactor power $60 \mathrm{MW}$ and maximum undisturbed thermal neutron flux $8 \times 1014 \mathrm{n} \cdot \mathrm{cm}-2 \cdot \mathrm{s}-1$. The core of CARR is inverse neutron trap compact core, uses U3Si2 -Al plate type fuel element, light water as coolant, heavy water as reflector. There are 9 horizontal channels and 21 vertical channels for various nuclear applications. CARR will be a good flat for the following application research:

- Neutron Scattering Experiment Study

- Radioisotope Production

- NTD for Monocrystaline Silicon

- Applications on Reactor Engineering Technology, including reactor I\&C technology. The control system of CARR is a complete digital system [5]. The whole control system consists 4 subsystems: monitoring and control system which takes the responsibility for monitoring and controlling main process systems, electrical system, ventilation and air-conditioning system, etc.; power regulating system which controls the reactor power of reactor; reactor protection system and mitigation system for ATWS(Anticipate Transient Without Scram) which are in charge of emergency shutdown of reactor. All these systems adopt digital technology, and are interlinked by $10 / 100 \mathrm{Mbps}$ self-adaptive redundant optic fiber industry Ethernet ring network (Fig 1).

The digital control system of CARR provide a solid basis for the future experiment and test of new control technology, i.e., AI technology, because it is easy and flexible for control computer to realize new control algorithm just by programming but without alternating the hardware of system. Operation data recorded by digital control system can also supply valuable reference for future experiment or test of AI technology.

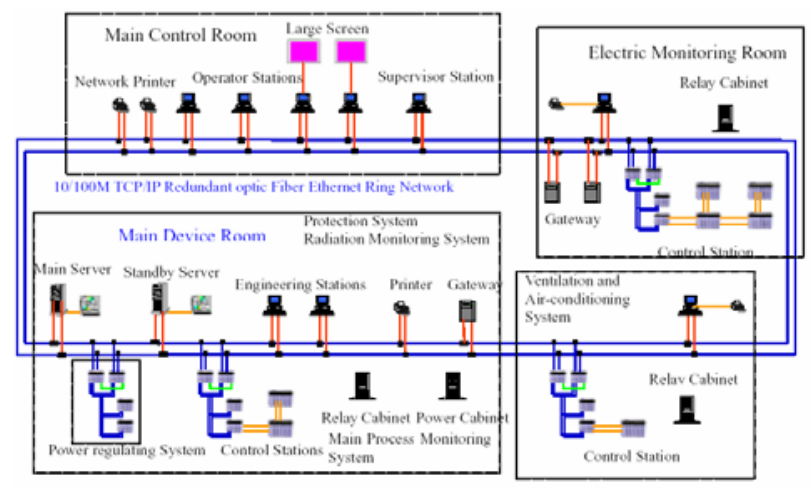

Fig. 1: Network Diagram of the control system of CARR.

Reactor power regulating system, one of the subsystem of the control system of CARR, controls the most important variable of reactor-reactor power by controlling 6 control rods of CARR. There are totally 6 control rods, 2 safety rods driven by hydraulic drive mechanisms, 4 shim rods driven by electromagnetic drive mechanism. After 2 safety rods is lifted up to the top of reactor, 4 shim rods are lifted slowly one by one, till reactor power reach the fixed value. Real time signal of reactor power is collected by power regulating system in every sample time.

In order to control the reactor power stably, necessary algorisms is adopted. The present algorithms is based on classical PID control theory, and fulfilled by a program module running in the control computer. Although simulation computation shows that the classical PID control algorisms have good performance, but the main disadvantages are:

1) There are 2 algorisms for regulation function and automatic function individually, that increase the complexity of the whole control program;

2) Even though the PID parameters have been determined by simulation computation, the tuning of PID parameters is prerequisite during commissioning of system, which is a time cost process. 
As a starting point of AI research, a fuzzy logic controller (FLC) for control of reactor power of CARR is presented in this paper. FLC has been implemented successfully in reactor fields [6-9], so it will easier and feasible for CARR to carry out the future experiment and test on real reactor. Another reason of choosing FLC as starting point of AI research is better performance, or even equivalent performance as conventional PID controller will be a good demonstration of AI technology. In fact the FLC presented in this paper can not only stabilize the reactor power during steady condition, but also increase or decrease reactor power automatically, and particularly the FLC can start the reactor automatically. As I explain latter in this paper the FLC act as a experienced operator with just one fuzzy logic adapted for all these operation mode.

\section{Fuzzy logic controller for controlling of the reactor power of CARR}

There are 4 factors which have impact on power regulating system of CARR:

-Firstly CARR is a research reactor, all the heat will be released to the air. There is not turbine for electricity generation;

-Secondly the core of CARR is small, and the reflector outsides the core can flatten the neutron flux, so the neutron flux peak is not important, there is no need for power distribution control;

-Thirdly the reactivity of reactor is controlled by control rods, there is not boron system;

-Finally the flow of main coolant system will not change during power operation, there is no need for coolant flow regulation.

These 4 factors simplify the power regulating system of CARR. The main task of this system is to control the reactor power automatically during starting-up, power transition, and steady-state operation process. The system receive the neutron flux signal detected by neutron detector, compare the real reactor power with the desired reactor power, compute the velocity of control rods via certain algorithm, and output the velocity signal to control rods driver mechanism. The whole closed-loop is showed by figure 2 .

Usually the velocity of control rods is proportional to the difference between desired reactor power and real reactor power, but according to the operation experience of operators, another parameterthe reactor power period-should be taken into account when determine the velocity of the control rods. If the period is very small, the control rods must be holden or inserted even if the power difference is negative large. Based on these considerations, a fuzzy logic controller with 2 input-reactor power difference and power period- and 1 output-velocity of control rods- is designed step by step.

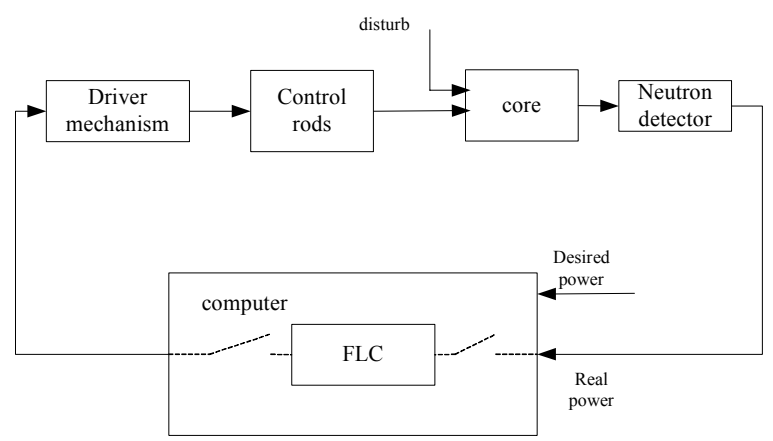

Fig. 2: Diagram of closed loop system.

Step 1 Compute the inputs

The power difference is computed according to the equation below:

$$
D P=\frac{N_{R}-N_{D}}{N_{D}} \times 100 \%
$$

Where DP is power difference, $N_{R}$ is real reactor power, $\mathrm{N}_{\mathrm{D}}$ is desired reactor power.

The power period is computed according to the equation below:

$$
P T=\frac{\frac{N(t)+N(t-T)}{2}}{\frac{N(t)-N(t-T)}{T}}
$$

Where $\mathrm{P}_{\mathrm{T}}$ is power period(s), $\mathrm{T}$ is sampling cycle time of computer, $\mathrm{N}(\mathrm{t})$ is the reactor power at current sampling time, $\mathrm{N}(\mathrm{t}-\mathrm{T})$ is reactor power at last sampling time.

Step 2 Fuzzify the inputs and output

1) Reactor power difference $D P$

We define 7 linguistic variables for DP within the range of $[-10 \% 10 \%]$ : negative big (NB), negative middle (NM), negative small (NS), near zero (NZ), positive small (PS), positive middle (PM), positive big (PB), the membership functions are shown below in figure 3. If DP beyond $10 \%$, it is also positive big, the degree of member in PB is 1 ; if DP beyond $-10 \%$, it is also negative big, the degree of member in NB is 1 . Sshaped function is selected for $\mathrm{NB}$ and $\mathrm{PB}$, triangular membership function is selected for others linguistic variable.

2) Reactor power period PT

We define 4 linguistic variables for PT: negative (NEG), positive small (PS), positive middle (PM), positive big (PB), membership functions are shown in figure 4. S-shaped function with parameters $\left[\begin{array}{ll}0 & 0\end{array}\right]$ is selected for negative PT, which mean the degree of member in NEG is 1 for any negative period, and we 


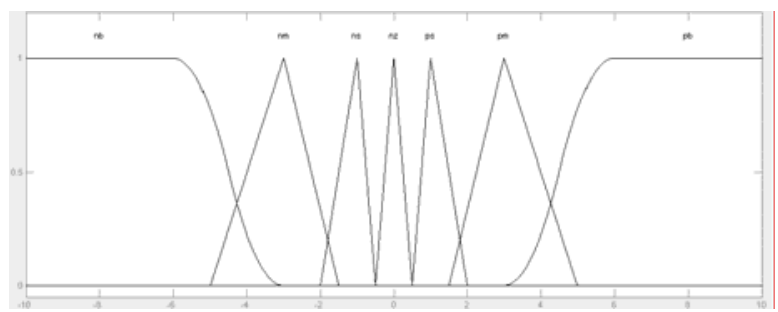

Fig 3: Membership functions of DP.

don't discern negative small, negative middle, negative big any more. Trapezoidal membership function is selected for PS, triangular membership function is for PM, s-shaped membership function is for $\mathrm{PB}$

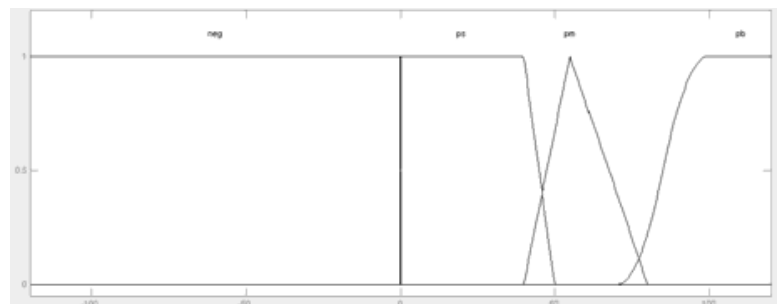

Fig 4: Membership functions of PT.

3) Velocity of control rods

We define 7 linguistic variables for velocity of control rods $\mathrm{V}$ within the range of $[-4 \mathrm{~mm} / \mathrm{s} 4 \mathrm{~mm} / \mathrm{s}]$ : insertion big (IB), insertion middle (IM), insertion small (IS), non action (NC), withdraw small (WS), withdraw middle (WM), and withdraw big (WB). Membership functions are shown in figure 5. Because the velocity control rods of CARR can be regulated successively, so we can select triangular membership function for all linguistic variables. There is no overlap between these variables.

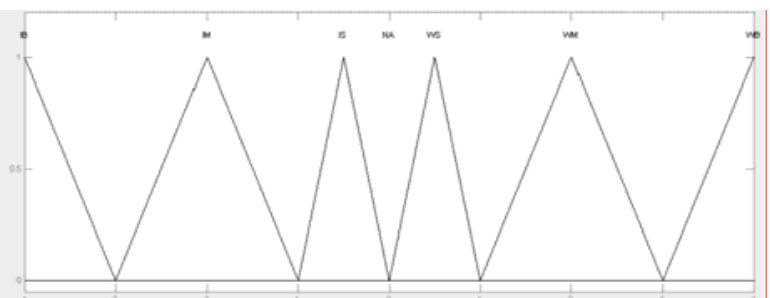

Fig 5: Membership functions of $\mathrm{V}$.

Step 3 Define the rule base

Definition of the rule base is the key step for FLC of CARR. As described before, there are 2 inputs and 1 output, we can extract the rule base for these 3 variables based on operation experience of operators. The basic ideas for operating the control rods is that, if the real reactor power is above the desired power, operators insert control rods; if the real reactor power is below the desired power, operators withdraw control rods. The reactor power period must be maintained longer than safety limit whenever the control rods are inserted or withdrew, i.e. if period is very short, operators must insert control rods even if the real power is below the desired power.

These basic ideas can be translated into the following 28 rules, which can be summarized in table 1.

\begin{tabular}{|c|c|c|c|c|c|c|c|}
\hline DP & NB & NM & NS & NZ & PS & PM & PB \\
\hline PT & V & V & V & V & V & V & V \\
\hline NEG & WB & WB & WM & NA & IS & IS & IM \\
\hline PB & WB & WM & WS & NA & IS & IM & IB \\
\hline PM & WM & WS & IS & IS & IM & IB & IB \\
\hline PS & IS & IS & IM & IB & IB & IB & IB \\
\hline
\end{tabular}

Table 1: Rule base for the FLC.

Every rule adopts AND (MIN) logic operator, and MIN method for implication of each rule. MAX method is adopted for aggregation of outputs of all these rules. Centroid method is adopted for defuzzification of the aggregation result.

\section{Simulation model for a closed loop system}

To evaluate the performance of the FLC designed in Chapter 3, mathematic models of the whole closed loop system (showed in Fig 2) are set up.

\subsection{Neutron physics model}

We adopt one-group neutron dynamic equation to compute the transient process of reactor power:

$$
\begin{aligned}
& \frac{d n(t)}{d t}=\frac{\rho(t)-\beta}{\Lambda} \bullet n(t)+\lambda c(t)+q \\
& \frac{d c(t)}{d t}=\frac{\beta}{\Lambda} \bullet n(t)-\lambda c(t)
\end{aligned}
$$

Where $n(t)$ is neutron density, $1 / \mathrm{cm}^{3} ; \rho(\mathrm{t})$ is reactivity, $\triangle \mathrm{k} / \mathrm{k} ; \mathrm{c}(\mathrm{t})$ is effective one-group precursor concentration, $1 / \mathrm{cm}^{3} ; \beta$ is effective delayed neutron fraction; $\Lambda$ is neutron generation time, $s ; \lambda$ is effective one grout delayed neutron decay constant., $\mathrm{s}^{-1} ; \mathrm{q}$ is neutron source term caused by $\gamma$-induced neutron, $1 / \mathrm{s} \cdot \mathrm{cm}^{3}$.

Reactor power $\mathrm{N}(\mathrm{t})$ is proportional to neutron density $n(t)$, which is showed in equation (4-1):

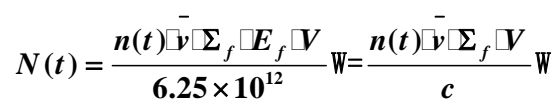

Where $\bar{v}$ is average speed of neutron, $\mathrm{cm} / \mathrm{s} ; \Sigma_{\mathrm{f}}$ is macro fission cross section, $\mathrm{cm}^{-1} ; \mathrm{E}_{\mathrm{f}}$ is fission energy of nuclei transferred into heat energy, Mev; $c$ is fissions per second which produce $1 \mathrm{~W}$ heat energy, $1 / \mathrm{s} \cdot \mathrm{W} ; \mathrm{V}$ is volume of reactor active area, $\mathrm{cm}^{3}$ 。We 
know from reactor theory that all these parameters are constant.

$$
\text { Let } C=\frac{\bar{v} \llbracket \Sigma_{f} \amalg V}{c}\left(\mathrm{~W} \cdot \mathrm{cm}^{-3}\right), \text { then } N(t)=C \sqsubset n(t)
$$

If equation (4-1) is multiplied by $\boldsymbol{C}$, we can derive equation (4-3) below:

$$
\begin{aligned}
& \frac{d N(t)}{d t}=\frac{\rho(t)-\beta}{\Lambda} \cdot N(t)+\lambda C(t)+Q \\
& \frac{d C(t)}{d t}=\frac{\beta}{\Lambda} \bullet N(t)-\lambda C(t)
\end{aligned}
$$

Where $\mathrm{N}(\mathrm{t})$ is reactor power, $\mathrm{W} ; \mathrm{C}(\mathrm{t})=\mathrm{C} \cdot \mathrm{c}(\mathrm{t}), \mathrm{W}$; $Q=C \sqcap, \mathrm{W} / \mathrm{s}$.

\subsection{Heat transfer model}

There are 2 kinds of fuel assemble in reactor core of CARR, standard fuel and follower fuel, we set up models separately.

\subsubsection{Heat transfer model for standard fuel}

Model is represented by equation below (4-4):

$$
\left\{\begin{array}{l}
\left(M_{f e 1} C_{f e 1}+M_{z 1} C_{z 1}\right) \frac{d \overline{T_{f e 1}(t)}}{d t}=P(t) \sqcap \alpha_{1}-P_{11}(t) \\
P_{11}(t)=A_{1} \llbracket h_{1}\left(\overline{T_{f e 1}(t)}-\overline{T_{c 1}(t)}\right) \\
M_{c 1} C_{c 1} \frac{d \overline{T_{c 1}(t)}}{d t}=P_{11}(t)-P_{12}(t) \\
\left.P_{12}(t)=2 m_{c 1}(t) C_{c 1} \overline{T_{c 1}(t)}-T_{i 11}\right)
\end{array}\right.
$$

Where $\boldsymbol{M}_{\text {fel }}$ is the total mass of standard fuel, $\mathrm{g}$; $C_{\text {fel }}$ is specific heat of standard fuel assemble, $\mathrm{J} / \mathrm{g} \cdot{ }^{\circ} \mathrm{C}$; $\boldsymbol{M}_{z 1}$ is total mass of cladding of standard fuel element, $\mathrm{g} ; C_{z 1}$ is specific heat of cladding of standard fuel element, $\mathrm{J} / \mathrm{g} \cdot{ }^{\circ} \mathrm{C} ; \overline{T_{f e 1}(t)}$ is average temperature of standard fuel assemble, ${ }^{\circ} \mathrm{C} ; \boldsymbol{P}(\boldsymbol{t})$ is reactor power, $\mathrm{W}$; $\alpha_{1}$ is power fraction of standard fuel assemble; $\boldsymbol{P}_{11}(t)$ is transferred power from standard fuel assemble to coolant in standard fuel assemble channel, $\mathrm{W} ; \boldsymbol{A}_{1}$ is total heat transfer area of standard fuel assemble, $\mathrm{m}^{2}$; $h_{1}$ is heat transfer coefficient of standard fuel assemble, $\mathrm{W} / \mathrm{m}^{2} \cdot{ }^{\circ} \mathrm{C} ; \overline{T_{c 1}(t)}$ is average temperature of coolant in standard fuel assemble channel, ${ }^{\circ} \mathrm{C} ; \boldsymbol{M}_{c 1}$ is total mass of coolant in standard fuel assemble channel, $\mathrm{g} ; \boldsymbol{C}_{c 1}$ is specific heat of coolant in standard fuel assemble channel, $\mathrm{J} / \mathrm{g} \cdot{ }^{\circ} \mathrm{C} ; \boldsymbol{P}_{12}(t)$ is power taken away by coolant in standard fuel assemble channel, $\mathrm{W} ; \boldsymbol{m}_{\mathrm{c} 1}(t)$ is flow rate of coolant in standard fuel assemble channel, $g / s$; $\boldsymbol{T}_{\boldsymbol{i n} 1}$ is inlet temperature of coolant in standard fuel assemble channel, ${ }^{\circ} \mathrm{C}$.

\subsubsection{Heat transfer model for follower fuel}

Model is represented by equation below (4-5):

$$
\left\{\begin{array}{l}
\left(M_{f e 2} C_{f e 2}+M_{z 2} C_{z 2}\right) \frac{d \overline{T_{f e 2}(t)}}{d t}=P(t) \sqcap \alpha_{2}-P_{21}(t) \\
\left.P_{21}(t)=A_{2} \llbracket h_{2} \llbracket \overline{T_{f e 2}(t)}-\overline{T_{c 2}(t)}\right) \\
M_{c 2} C_{c 2} \frac{d \overline{T_{c 2}(t)}}{d t}=P_{21}(t)-P_{22}(t) \\
P_{22}(t)=2 m_{c 2}(t) C_{c 2}\left(\overline{T_{c 2}(t)}-T_{i n 2}\right)
\end{array}\right.
$$

Where $\boldsymbol{M}_{f e 2}$ is the total mass of standard fuel, $\mathrm{g}$; $C_{\text {fe2 }}$ is specific heat of standard fuel assemble, $\mathrm{J} / \mathrm{g} \cdot{ }^{\circ} \mathrm{C}$; $\boldsymbol{M}_{z 2}$ is total mass of cladding of standard fuel element, $\mathrm{g} ; C_{z 2}$ is specific heat of cladding of standard fuel element, $\mathrm{J} / \mathrm{g} \cdot{ }^{\circ} \mathrm{C} ; \overline{T_{f e 2}(t)}$ is average temperature of standard fuel assemble, ${ }^{\circ} \mathrm{C} ; \boldsymbol{P}(\boldsymbol{t})$ is reactor power, W; $\alpha_{2}$ is power fraction of standard fuel assemble; $\boldsymbol{P}_{21}(t)$ is transferred power from standard fuel assemble to coolant in standard fuel assemble channel, $\mathrm{W} ; \boldsymbol{A}_{2}$ is total heat transfer area of standard fuel assemble, $\mathrm{m}^{2}$; $\boldsymbol{h}_{2}$ is heat transfer coefficient of standard fuel assemble, $\mathrm{W} / \mathrm{m}^{2} \cdot{ }^{\circ} \mathrm{C} ; \overline{T_{c 2}(t)}$ is average temperature of coolant in standard fuel assemble channel, ${ }^{\circ} \mathrm{C} ; \boldsymbol{M}_{\mathrm{c} 2}$ is total mass of coolant in standard fuel assemble channel, $\mathrm{g} ; \boldsymbol{C}_{\mathrm{c} 2}$ is specific heat of coolant in standard fuel assemble channel, $\mathrm{J} / \mathrm{g} \cdot{ }^{\circ} \mathrm{C} ; \boldsymbol{P}_{22}(t)$ is power taken away by coolant in standard fuel assemble channel, $\mathrm{W} ; \boldsymbol{m}_{\mathrm{c} 2}(t)$ is flow rate of coolant in standard fuel assemble channel, $\mathrm{g} / \mathrm{s}$; $\boldsymbol{T}_{\text {in } 2}$ is inlet temperature of coolant in standard fuel assemble channel, ${ }^{\circ} \mathrm{C}$.

\subsubsection{Average fuel temperature and coolant temperature model}

Model is represented by equation below (4-6):

$$
\left\{\begin{array}{l}
\overline{T_{f e}(t)}=\frac{\left(\overline{T_{f e 1}(t)} V_{f e 1}+\overline{T_{f e 2}(t)} V_{f e 2}\right)}{V_{f e 1}+V_{f e 2}} \\
\overline{T_{c}(t)}=\frac{\left(\overline{T_{c 1}(t)} V_{c 1}+\overline{T_{c 2}(t)} V_{c 2}\right)}{V_{c 1}+V_{c 2}}
\end{array}\right.
$$

Where $\overline{T_{f e}(t)}$ is average temperature of fuel, ${ }^{\circ} \mathrm{C}$; $\overline{T_{c}(t)}$ is average temperature of coolant, ${ }^{\circ} \mathrm{C} ; V_{\text {fel }}$ is the volume of standard fuel, $\mathrm{cm}^{3} ; V_{\text {fez }}$ is volume of follower fuel, $\mathrm{cm}^{3} ; V_{\mathrm{c} 1}$ is volume of coolant in standard fuel assemble channel, $\mathrm{cm}^{3} ; V_{c 2}$ is volume of coolant in follower fuel assemble channel, $\mathrm{cm}^{3}$;

\subsubsection{Temperature feedback model}

Model is represented by equation below (4-7):

$\left\{\begin{array}{l}\rho_{f e}=\left(\overline{T_{f e}(t)}-\overline{T_{f e}(0)}\right) * k_{f e} \\ \rho_{c}=\left(\overline{T_{c}(t)}-\overline{T_{c}(0)}\right) * k_{c}\end{array}\right.$

Where $\rho_{f e}$ is reactivity feedback of fuel, $\boldsymbol{k}_{f e}$ is reactivity feedback coefficient of fuel, $\rho_{c}$ is reactivity feedback of coolant, $\boldsymbol{k}_{c}$ is reactivity feedback 
coefficient of coolant, $\overline{T_{f e}(\mathbf{0})}$ is initial temperature of fuel, $\overline{T_{c}(\mathbf{0})}$ is initial temperature of coolant.

\subsection{Reactor power measurement model}

The neutron detector and signal processing unit can be modeled by a simplified model: one-order delay model, which is represented by transfer function below:

$$
N_{\mathrm{m}}(S)=\frac{1}{0.1 S+1} N(S)
$$

Where $\mathrm{N}(\mathrm{s})$ is actual reactor power, $\mathrm{N}_{\mathrm{m}}(\mathrm{s})$ is measurement of reactor power, $\mathrm{S}$ is Laplacian.

\subsection{Fuzzy logic controller model}

The detail of FLC of CARR is described in chapter 3 . We can set up easily the FLC simulation model by fuzzy toolbox in SIMULINK flat.

\subsection{Interlock logic model for motion of control rods}

As mentioned before, there are 4 control rods for controlling of reactor power of CARR, and the maximum position difference between these 4 rods is $6 \mathrm{~mm}$. To keep position difference within $6 \mathrm{~mm}$, all these control rods are inserted or withdrew in a certain way:

- Just one rod can be moved every time, simultaneous move of rods is forbidden by logic interlock;

- If velocity of control rods which is computed by FLC via fuzzy algorithm is positive, the rod with lowest position is withdrew; whereas if velocity of control rods is negative, the rod with highest position is inserted.

- If velocity of control rods is zero, all control rods are stopped.

This kind of logic interlock is realized in control computer of power regulating system of CARR by a program developed by contact language. The simulation model for this motion logic interlock can also be realized in SIMULINK flat. STATEFLOW language, which is based on finite state machine theory $[10,11]$, supported in MATLAB, and a good tool to simulate logic relationship between different objects.

\subsection{Driver mechanism model}

The driver mechanism of control rod of CARR is constituted by 3 parts: stepping motor, screwer, and magnetic circuit. The drive mechanism model of control rod of CARR is showed in figure 6. The integral unit with a discretizing block simulates the stepping motor and screwer; the "FCN" block and "BACKLASH" block simulate the displace delay property of magnetic circuit [12].

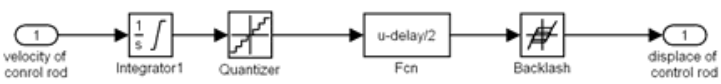

Fig 6: Driver mechanism model.

\subsection{Control rod worth model}

The integral worth curve of one rod is shown in figure 7 , and the model is realized by interpolation function of MATLAB.

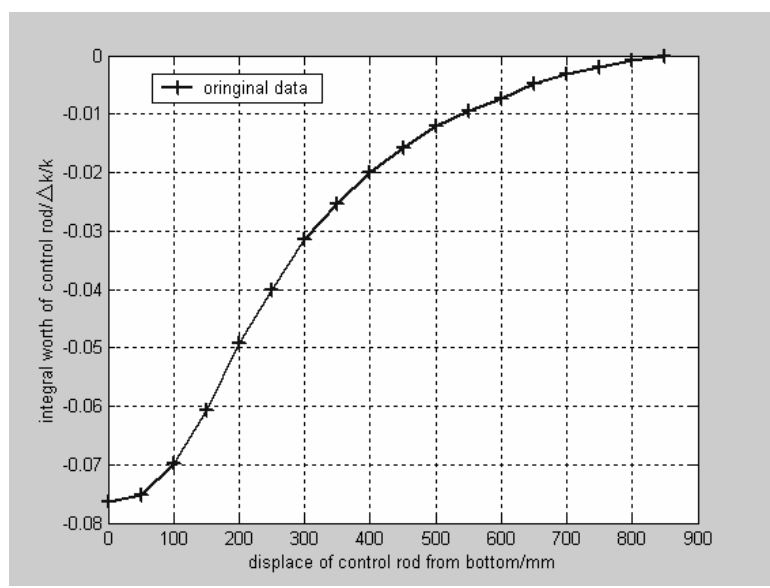

Fig 7: Integral rod worth of one control rod.

\section{Simulation computation of the closed loop system}

Based on the simulation models set up in chapter 4, the simulation model of the whole closed loop system (showed in figure 2) is built up. 4 processes are simulated by the simulation model, these 4 processes are:

1) Reactor starts up automatically from subcriticality to criticality, and then power is increased automatically and exponentially from low power level to $10 \mathrm{Mw}$;

2) Reactor power is increased at $2000 \mathrm{~s}$ automatically and linearly from $10 \mathrm{Mw}$ to $60 \mathrm{Mw}$;

3) Step reactivity disturb is inserted into the closed loop at 3500s when reactor power is at $60 \mathrm{Mw}$, the reactor power is stabilized automatically after a short period of transient;

4) Reactor power is decreased at $4000 \mathrm{~s}$ automatically and exponentially from $60 \mathrm{Mw}$ to $600 \mathrm{kw}$.

Process 1), 2), 4) are power transient processes, and process 3 ) is a steady process. The 4 processes are shown by calculation curves of different important 
parameters: actual reactor power $\mathrm{N}_{\mathrm{T}}$, desired reactor power $\mathrm{N}_{\mathrm{D}}$, power period $\mathrm{PT}$, fuel and coolant temperature, displacement of control rods (Figure 8Figure 12).

The initial conditions for the simulation are:

- All control rods are in the bottom of reactor;

- The initial reactor is assumed to be $0.02 \mathrm{w}$, which is caused by $\gamma$ induced neutrons;

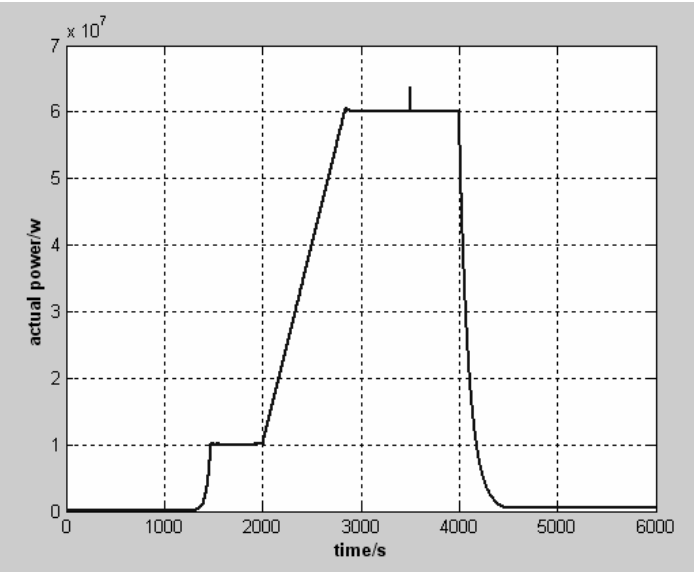

Fig 8: Reactor actual power.

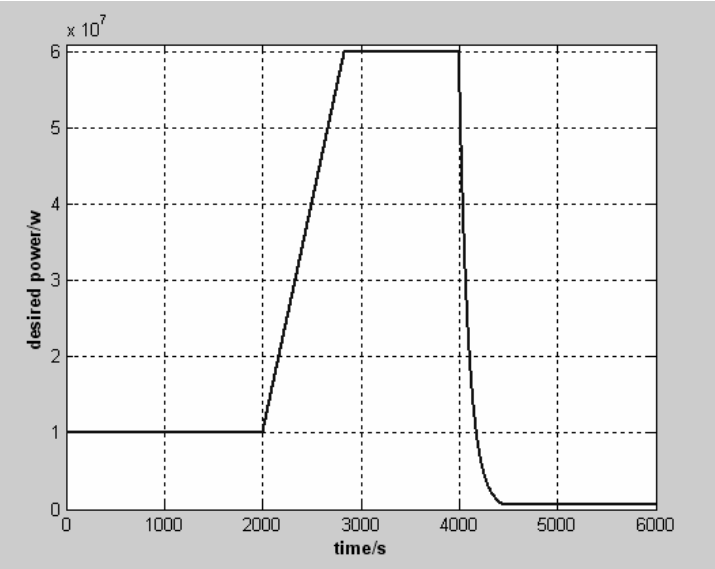

Fig 9: Reactor desired power.

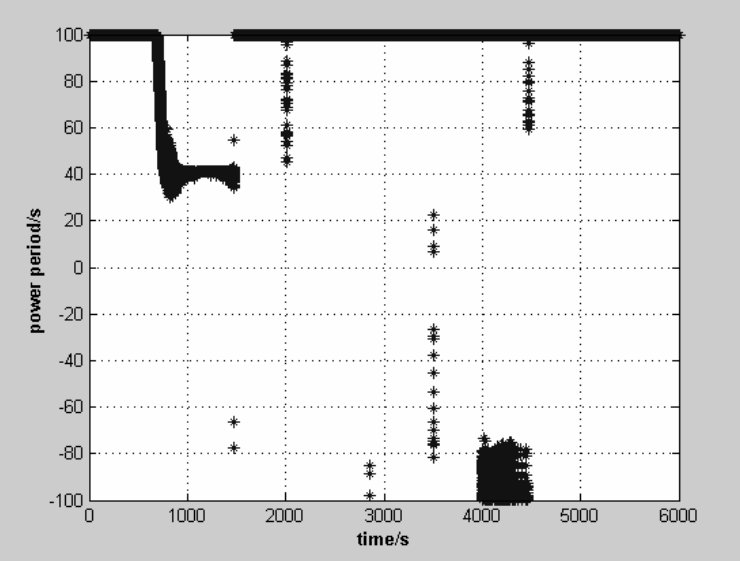

Fig 10: Reactor power period.

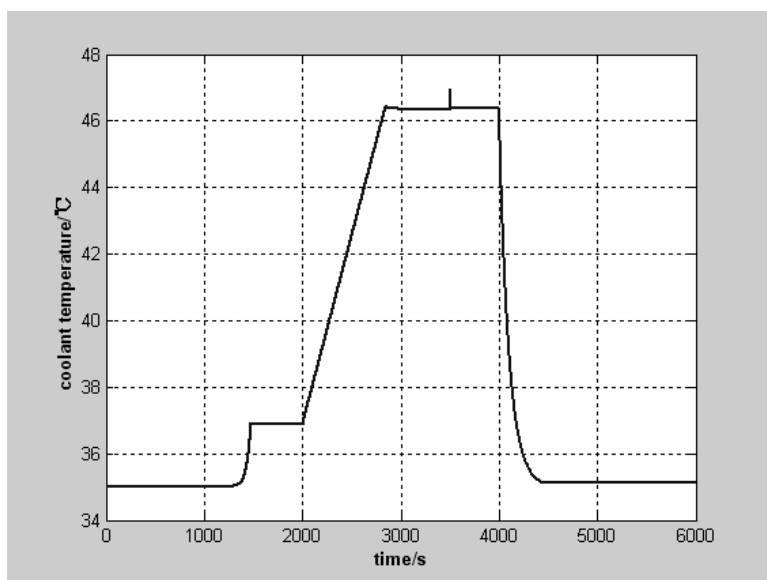

Fig 11: Coolant temperature.

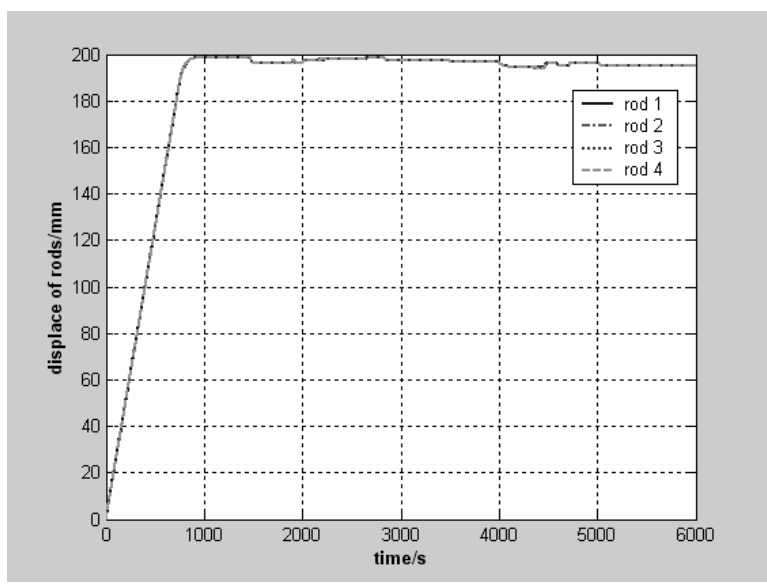

Fig 12: Control rods displacement.

We can see from the simulation curve that the FLC designed in chapter 3 works very well in all these process. With the control of the FLC, reactor can be started up stably, and reactor power can also be transited between different power levels stably. In steady state the FLC with prompt responsibility to disturb is able to stabilize the reactor power quickly, and to keep reactor in a safe state.

\section{Conclusions}

As a beginning of AI research on CARR flat, a new type of fuzzy logic controller for controlling reactor power of CARR is designed in this paper. The FLC mimics the operation of good operator. It makes decision on the direction of motion of control rods, and how fast all control rods move, by fuzzy logic inference process.

To evaluate the performance of the FLC, simulation computation is realized in this paper. All simulation models of the closed loop system are set up in the simulation flat SIMULINK. 4 normal operation processes are simulated in this paper: reactor starting up process, reactor power increasing process, process 
under step reactivity disturb, and reactor power decreasing process. We can make the following conclusion on the FLC from the simulation result:

1) Simulation computation shows very good performance of the FLC, and the FLC has the adaptability itself to be used not only in the steady state but also in the normal operation transient without any revision of the rules and membership function, etc. of the inference system of the FLC;

2) Unlike the classical controller design, theoretical analysis of the whole closed loop system is not requested for the design of FLC, if we have accumulated much operation experience, then fuzzy logic is very good option to transfer the operation experience to direct control command;

3) The rules base and membership functions can be easily understood by operators because of the linguistic expression consistent with the practical operation;

4) For the first time the fuzzy logic is used in transient process of reactor, the simulation shows that the FLC is a safe controller with prompt responsibility to disturb; the FLC is also able to complete the normal operation automatically in a short time, which simplify greatly the reactor operations during transient process.

\section{Acknowledgement}

I would like to express my gratitude to Dr. Da Ruan, it is him to open the door of a new field-Artificial Intelligence- to me. Many years of research of international institute shows many benefits of AI, which will a good option to enhance the safety and economy of nuclear power plant, especially for the new generation nuclear power plant. Presently the cooperation between China Institute of Atomic Energy and $\mathrm{SCK} \cdot \mathrm{CEN}$ has been carried out, which will prompt certainly the progress of AI in Chinese nuclear fields.

\section{References}

[1] D. Ruan, Modern Approaches and Advanced Application for Plant Surveillance and Diagnostics: An Overview, Power Plant Surveillance and Diagnostics, 2001.

[2] D. Ruan, Guest Editor's Preface, Computational Intelligence in Nuclear Applications: Lessons Learned and Recent Developments, 2005.

[3] J.W. Hines, R.E. Uhrig, Trends in Computational Intelligence in Nuclear Engineering, Computational Intelligence in Nuclear Applications: Lessons Learned and Recent Developments, 2005.
[4] Y.K. Shi, The China Advanced Research Reactor Project, 13th International Conference on Nuclear Engineering, Beijing, China, May 16-20, 2005.

[5] H. Zeng, Implementation of Digital Control \& Protection Systems of China Advanced Research Reactor, 13th International Conference on Nuclear Engineering, Beijing, China, May 16-20, 2005.

[6] D. Ruan, Controlling the Power Output of a Nuclear Reactor with Fuzzy Logic, Information Sciences $110: 151-177,1998$.

[7] D. Ruan, Implementation of Adaptive Fuzzy Control for a Real-Time Control Demo-Model, Real-Time System, 21: 219-239, 2001.

[8] D. Ruan, Initial Experiment on Fuzzy Control for Nuclear Reactor Operations at the Belgian Reactor 1, Nuclear Technology, Vol. 143, Aug. 2003.

[9] F. Adda, Ddsign of an Intelligent Fuzzy Logic Controller for a Nuclear Research Reactor, Computational Intelligence in Nuclear Applications: Lessons Learned and Recent Developments, 2005.

[10] Harel and David, Statecharts: A Visual Formalism for Complex Systems, Science of Computer Programming 8: 231-274, 1987.

[11] Hatley, Derek J. and Imtiaz A. Pirbhai, Strategies for Real-Time System Specification, Dorset House Publishing Co., Inc., NY, 1988.

[12] J.G. Zhang, Experiment Study on Dynamic Property of a new electromagnet Drive for Reactor Control rod, Chinese Journal of Nuclear Science of Engineering, 23(2), Jun 2003. 